\title{
COMO MANEJAR VACAS LEITEIRAS DURANTE O PERÍODO DE TRANSIÇÃO? NOVAS ESTRATÉGIAS DE CONTROLE DOS DISTÚRBIOS METABÓLICOS- UMA REVISÃO.
}

\author{
ROSA, Patrícia Pinto da ${ }^{1^{*}}$ \\ CHESINI, Rodrigo Garavaglia ${ }^{2}$ \\ MOTA, Gilliany Nessy ${ }^{3}$ \\ XAVIER, Amanda Azambuja da Silva ${ }^{1}$ \\ SEDREZ, Pamela Aristimunho ${ }^{3}$ \\ GRAZZIOTIN, Rodrigo Chaves Barcellos ${ }^{1}$ \\ CAMACHO, Juliana da Silva ${ }^{4}$ \\ ROLL, Victor Fernando Buttow ${ }^{5}$
}

\begin{abstract}
RESUMO: A produção de leite no Brasil tem aumentado nos últimos anos, devido aos investimentos em genética e dietas balanceadas, onde animais de alta produção tem seu metabolismo forçado ao limite para atender a demanda produtiva. O objetivo desta revisão foi abordar informações existentes na literatura sobre o período de transição de vacas leiteiras, destacando práticas de manejos nutricionais neste período, assim como estratégias de prevenção das desordens metabólicas. O período de transição consiste em três semanas antes até três semanas após o parto, é altamente relevante para a saúde da vaca leiteira, afetando diretamente sobre a produção e rentabilidade. O balanço energético negativo (BEN) afeta a grande maioria dos animais neste período, causando desordens no equilíbrio energético da vaca, com aumento dos níveis no sangue de ácidos graxos não esterificados (AGNE) e betahidroxibutirato (BHB) acarretando em distúrbios metabólicos como esteatose hepática, cetose, febre do leite, deslocamento de abomaso, assim como problemas reprodutivos e mastite. $\mathrm{O}$ uso de aditivos na dieta destes animais é alternativa eficaz na prevenção de doenças metabólicas e como incremento na ingestão de matéria seca (IMS), juntamente com outras estratégias que auxiliam na redução das disfunções metabólicas e de imunossupressão durante o período de transição, tais como limitar a produção de leite durante a primeira semana de lactação com ordenha incompleta duas vezes ao dia, pois reduz o balanço energético negativo e consequentemente os níveis de AGNE e BHB no sangue, não comprometendo o resto da lactação.
\end{abstract}

Palavras Chave: Condição Corporal. Ingestão De Matéria Seca. Produção De Leite

\section{HOW TO HANDLE DAIRY COWS DURING THE TRANSITION PERIOD? NEW METABOLIC DISORDERS CONTROL STRATEGIES- A REVIEW}

SUMMARY: Milk production in Brazil has increased in recent years due to investments in genetics and balanced diets, where high production animals have their metabolism forced to the limit to meet the productive demand. The objective of this review was to discuss the literature on the transition period of dairy cows, highlighting practices of nutritional management during this period, as well as strategies for the prevention of metabolic disorders. The transition period consists of three weeks before up to three weeks postpartum, is highly relevant to dairy cows health, directly affecting production and profitability. The negative energetic balance (BEN) affects the great majority of the animals in this period, causing disorders in the cow's energy balance, with increased levels of nonesterified fatty acids (NEFA) and betahydroxybutyrate (BHB) leading to metabolic disorders such as hepatic steatosis, ketosis, milk fever, displacement of abomasum, as well as reproductive problems and mastitis. The use of additives in the diet of these animals is an effective alternative in the prevention of metabolic diseases and as an increase in dry matter intake (IMS), along with other strategies to help reduce metabolic dysfunctions and

\footnotetext{
${ }^{1}$ Doutoranda no Programa de Pós-Graduação em Zootecnia-Universidade Federal de Pelotas

${ }^{2}$ Graduando em Zootecnia-Universidade Federal de Pelotas

${ }^{3}$ Mestranda no Programa de Pós-Graduação em Zootecnia-Universidade Federal de Pelotas

${ }^{4}$ Zootecnista formada pela Universidade Federal de Pelotas

${ }^{5}$ Professor Adjunto Departamento de Zootecnia-Universidade Federal de Pelotas
} 
immunosuppression during the transition period, such as limiting milk production during the first week of lactation with incomplete milking twice a day, because it reduces the negative energy balance, and consequently the levels of NFA and BHB in the blood, without compromising the rest of the lactation

Keywords: Body Condition. Dry Matter Intake. Milk Production

\section{INTRODUÇÃO}

O Brasil é reconhecido mundialmente pelo seu potencial na produção leiteira, em quarenta anos a produção brasileira quadriplicou, produzindo 35,1 bilhões de litros no ano de 2018. Dentre os estados produtores de leite, Minas Gerais é o maior produtor de leite do Brasil (8,9 bilhões de litros), a região Sul do País é referência em termos de produtividade por vaca (2.966 litros/vaca/ano), bem acima da média nacional (1.709 litros/vaca/ano), Castro no Paraná é a capital brasileira do leite (produtividade média 7.478 litros), (EMBRAPA, 2018). Este cenário nos indica que ocorreu aumento na produtividade animal com o passar dos anos, decorrente da seleção genética dos rebanhos, de melhorias e planejamento das dietas garantindo um aporte nutricional adequado a estes animais .

Maior produção de leite por vaca, significa exigir mais destes animais, onde vacas de alta produção tem seu metabolismo pressionado ao limite, afim de atender as demandas de todos os processos fisiológicos (INGVARTSEN; MOYES, 2013). Segundo Sordillo e Raphael (2013), estas exigências energéticas durante estes processos, são acentuadas no período de transição, decorrentes de mudanças ambientais, da dieta, e de socialização ocorridas, em relação ao manejo adotados durante a lactação.

O período de transição de uma vaca leiteira começa 21 dias antes do parto e 21 dias após o parto, sendo período de extrema importância para a saúde e produção dos animais, pois nesta fase a vaca passa por grandes mudanças hormonais (GRUMMER, 1995). Durante a fase de préparto a vaca diminui sua ingestão de matéria seca, mas ao mesmo tempo a demanda por nutrientes é alta e precisa ser suficiente para garantir o crescimento do feto e a síntese de leite (DRACKLEY, 1999). Nesta transição, alterações hormonais, metabólicas, fisiológicas e anatômicas que preparam a vaca para o parto e lactogênese, acabam por favorecer a ocorrência de distúrbios patológicos que acabam por prejudicar a eficiência produtiva da lactação, reduzir o desempenho reprodutivo e aumentar a taxa de descarte (HUZZEY et al., 2007).

A maioria dos problemas metabólicos e infecciosos como mastite, metrite, deslocamento de abomaso, retenção de placenta, hipocalcemia, cetose e acidose ruminal, acontecem neste período de transição (INGVARTSEN et al., 2013). Um dos mais preocupantes problemas é o balanço energético negativo (BEN), pois a vaca lactante aumenta a demanda por energia, mas não 
consegue ingerir a quantidade de alimento necessário para manter o equilíbrio nutricional adequado para atender todas as suas exigências, resultando em perda da condição corporal (LEBLANC, 2010).

O decréscimo da ingestão de matéria seca (IMS) é uma limitação física, pois o feto no terço final da gestação ocupa praticamente todo espaço possível na cavidade abdominal, diminuindo assim a capacidade do rúmen de expandir (GRUMMER et al., 2004). Os fatores hormonais e metabólicos comprometem a IMS e o sistema imune, pois a progesterona e o cortisol geram desordem na expressão dos genes reguladores do sistema imune (LIMA, 2011). No que diz respeito aos fatores metabólicos, segundo Ster et al. (2012), o aumento dos ácidos graxos não esterificados (AGNE) e do Betahidroxibutirato (BHB) circulantes, produzidos pela mobilização lipídica resultantes do BEN, decrescem a IMS.

Durante operíodo de transição, segundo Sepulveda-Varas et al. (2015) cerca de 56\% das doenças clínicas ou subclínicas observadas acontecem em sistemas pastoris, enquanto que 68\% dos casos observados são em regime estabulado como citado por Schirmann et al. (2016). Uma maneira de controlar todas estas alterações negativas e melhorar a eficiência produtiva destes animais, é a adoção de práticas que favoreçam o manejo ambiental e nutricional, da mesma forma, omonitoramento da saúde das vacas em período de transição (HUZZEY et al., 2007).

O objetivo desta revisão foi abordar informações existentes na literatura sobre o período de transição de vacas leiteiras, destacando práticas de manejos nutricionais neste período, assim como estratégias de prevenção das desordens metabólicas.

\section{DESENVOLVIMENTO}

\section{Período de Transição}

O período de transição consiste em três semanas antes até três semanas após o parto, é relevante para a saúde da vaca leiteira, afetando diretamente a produção e rentabilidade, onde algumas mudanças de adaptação acabam ocorrendo durante o final da gestação e início da lactação (DRACKLEY et al., 2005).

A utilização de programas de manejo nutricional e sanitário para vacas leiteiras em período de transição é importância para produtores e técnicos, onde na maioria das propriedades não há protocolos nutricionais e sanitários (LEBLANC et al., 2005). A utilização de alimentos de baixa qualidade, seguidos de dietas desbalanceadas, com restrição de alimento, somados a condições precárias de ambiência e conforto, afetam a saúde, o desempenho das lactações e reproduções subsequentes (HARDARSON; INGVARTSEN, 2005). 
Este período é marcado por mudanças, onde a vaca sofre alterações no seu ambiente físico e social, sendo transferida para o grupo de vacas secas pré-parto e após o parto para o grupo de vacas em lactação (FRIGGENS, 2003). Alguns animais são mais temerosos e se encontram em posição social inferior em um novo rebanho, de maneira que a formação de grupos de 40 a 100 animais é o mais indicado, pois proporciona maior facilidade de reconhecimento dos mesmos dentro do grupo. Grant; Albright, (2000), afirmam que alguns fatores tendem a interferir no tamanho do lote formado, como espaço de cocho, onde gera competição por água e alimento. Outro fator não menos importante são as interações sociais que existem no rebanho, que dependem do tamanho do espaço disponível para os animais circularem, que irá refletir no consumo de matéria seca e consequentemente na produção de leite dos lotes.

Quando a vaca chega ao final do seu período seco e prestes a entrar em lactação, o produtor deve tomar medidas para prevenção de distúrbios metabólicos como esteatose hepática, cetose, febre do leite, deslocamento de abomaso, assim como problemas reprodutivos e mastite (INGVARTSEN et al., 2013). Uma das medidas que devem ser adotadas para reduzir os riscos destes transtornos, é a elevação da energia da dieta durante as últimas semanas pré-parto e durante o início da nova lactação reduzindo as mudanças que acabam por agravar o estresse, contribuindo na prevenção da hipocalcemia e na redução na mobilização de reservas de tecido adiposo (CONTRERAS et al., 2010).

O NRC (2001) recomenda a utilização de diferentes níveis de exigências nutricionais na dieta das vacas leiteiras no período seco que antecedem o parto. Separar o rebanho em dois grupos de vacas pré-parto, garante um manejo mais eficiente na alimentação, pois vacas primíparas, costumam ter um consumo menor de alimentos e de maneira diferente que vacas multíparas (GRANT; ALBRIGHT, 2001). Uma maneira de separar em lotes vacas no período seco que antecedem o parto, seria um grupo com novilhas primíparas nas últimas três semanas pré-parto e um grupo com vacas multíparas no mesmo período Sniffen (1991). A vantagem de separar primíparas de multíparas nesta fase é a redução de competição por espaço no momento do descanso e por alimento, pois novilhas primíparas são beneficiadas quando separadas das vacas multíparas devido também ao tamanho corporal e a posição de subordinação dentro da hierarquia existente no grupo, pois primíparas são mais temerosas e pode acarretar em redução da ingestão de alimento e aumento da incidência de doenças metabólicas no início da lactação (GRANT; ALBRIGHT, 2001). Com a formação de grupos distintos facilita o fornecimento de dietas diferenciadas para atender a exigências nutricionais específicas, com o uso de aditivos como, sais aniônicos, ionóforos, vitaminas e minerais que beneficiam a vaca durante o terço final da gestação. 


\section{Balanço Energético Negativo (BEN)}

O período de transição é marcado pelo BEN, pois causa sérios impactos na fisiologia e desempenho das vacas leiteiras por se tratar de déficit energético, onde a demanda por energia é maior do que a sua ingestão (BAUMGARD et al., 2006). Durante o pré-parto a IMS diminui e tem início a colostrogênese, com feto ainda em crescimento, que elevam as demandas energéticas, proteicas e minerais do animal (ADEWUYI et al., 2005). Logo após o parto o pico de produção de leite ocorre entre a $4^{\mathrm{a}}$ e a $7^{\mathrm{a}}$ semana, por outro lado o pico de consumo de alimento acontece da $8^{\mathrm{a}}$ a $22^{\mathrm{a}}$ semana depois do parto, apresentando neste período do BEN o maior desequilíbrio entre a taxa de ingestão de alimentos e as necessidades nutricionais (INGVARTSEN; ANDERSEN, 2000).

O BEN é intensificado no início da lactação (CONTRERAS et al., 2010), com acentuada perda de peso corporal (PC) e de escore de condição corporal (ECC) dos animais, devido a intensa lipólise para suprir as crescentes demandas por energia para a mantença e produção de leite (LEBLANC, 2010). Além de prejudicar a rentabilidade da atividade leiteira, o BEN está associado a distúrbios metabólicos, atraso da ciclicidade reprodutiva e comprometimento do sistema imune (CHAPINAL et al., 2011).

Ao mobilizar suas reservas corporais para atender a demanda de energia, a lipólise aumenta e como consequência eleva a concentração de ácidos graxos não esterificados (AGNE) no sangue, além disso o aumento da lipólise e a redução da lipogênese também ocorrem devido a outros fatores que não se ligam a nutrição, mas sim a mecanismos de regulação endócrina estabelecido pela homeorrexia, que atuam reduzindo a mobilização tecidual (SHELDON, 2004). Segundo Ospina et al. (2010) todas estas mudanças são reguladas por mecanismos homeostáticos e homeorréticos. Os mesmos autores definem a homeorrexia como sendo responsável pela adaptação dos animais as diferentes fases da vida, com as mudanças coordenadas no metabolismo para conseguir suprir novos estados fisiológicos, que não sofrem influência da nutrição e de outros fatores externos. Conforme Roche et al. (2009), a homeostase é definida por processos de regulação para manter o equilíbrio metabólico em diferentes condições nutricionais ou ambientais.

\section{Ácidos Graxos Não Esterificados (AGNE) e Betahidroxibutirato (BHB)}

Drackley et al. (2005) afirmam que a demanda de glicose para síntese do leite após o parto é elevada, mas a IMS ainda é baixa, devido aos carboidratos da dieta serem fermentados no rúmen, reduzida quantidade de glicose é absorvida no trato digestivo. Logo a produção de ácido propiônico se torna insuficiente para toda a demanda sistêmica por glicose, intensificando a 
mobilização de reservas, elevando a concentração AGNE que serão captados pelo fígado (Drackey et al., 2001).

Elevada relação entre o hormônio do crescimento $(\mathrm{GH})$ e a insulina na corrente sanguínea de vacas no pós-parto, acaba por permitir a mobilização de ácidos graxos de cadeia longa de triglicerídeos (TG) oriundos do tecido adiposo, auxiliando na redução do BEN (ROCHE et al., 2009; LUCY et al., 2009). No tecido adiposo ocorre a liberação de ácidos graxos que circulam em forma de AGNE, atuando como principal fonte de energia para a vaca durante o BEN, conforme o mesmo aumenta, mais quantidades de AGNE são liberadas no sangue (TSIOULPAS et al., 2007). Essas adaptações que culminam no BEN e consumo das reservas corpóreas dos animais são visivelmente notadas pela diminuição do ECC. Segundo Reynolds et al. (2003), com a elevação da concentração de AGNE no sangue, mais ele é absorvido no fígado, podendo ser completamente oxidado a dióxido de carbono, fornecendo energia para o próprio fígado, como parcialmente oxidado para produção de corpos cetônicos que são liberados no sangue e sendo fonte de energia para outros tecidos, como também podem ser convertidos para TG.

Os AGNE são absorvidos pelo fígado e no processo de oxidação são reduzidos a dois carbonos e convertidos em acetil-Coa (acetilcoenzima A), na presença do oxaloacetato aderem ao ciclo do ácido cítrico (Ciclo de Krebs), onde são submetidos a uma série de reações, gerando energia e $\mathrm{CO}_{2}$. Na ausência de quantidades suficientes de oxaloacetato, o acetil-Coa é desviado para outras vias metabólicas, sendo transformado em acetato, precursor dos corpos cetônicos como o betahidroxibutirato (BHBA) e acetona (BEITZ, 1996).

Os corpos cetônicos (beta hidroxibutirato, acetona e aceto acetato) são metabólitos intermediários da oxidação de ácidos graxos e são fontes de energia (WITTWER, 2000). Entretanto, o fígado dos ruminantes apresenta capacidade limitada para oxidar completamente os AGNE pelo ciclo do ácido tricarbocílico e também de exportar os triglicerídeos como lipoproteínas de baixa densidade (VLDL). Nos últimos dias que antecedem ao parto, a eficácia do tecido hepático em esterificar AGNE em TG é elevada, (LITHERLAND et al., 2003), e como consequência, as vacas que recebem dietas típicas durante o período pré-parto, tendem a ter um aumento nas concentrações de TG no fígado no primeiro dia após o parto, atingindo o pico entre o $7^{\circ}$ e o $14^{\circ}$ dia (MOYES et al., 2009).

Com as altas taxas de mobilização lipídica acarretando na elevação da captação de AGNE pelo fígado e no aumento do acúmulo de triglicérides (TG) em certos casos, pode resultar em síndrome de lipidose hepática ou fígado gorduroso, podendo levar a outros distúrbios como a cetose (ARAUJO, 2009). Após o parto, teores séricos de AGNE e BHBA indicam a capacidade do metabolismo de certos animais em lactação de se adaptarem ao BEN, pois medem a mobilização e oxidação da gordura durante este período, que no momento do parto tendem a se 
elevar (HAMMON et al., 2009). Em estudos de LeBlanc et al. (2005), foram registrados aumentos da concentração de $\operatorname{AGNE}\left(\geq 0,4 \mathrm{mmol} / \mathrm{L}^{-1}\right)$ de 7 dias antes do parto, estando associado a risco de deslocamento de abomaso, retenção de placenta e queda na produção de leite. Valores superiores de BHBA (>1.200 mmol/ $\left.\mathrm{L}^{-1}\right)$ na primeira ou segunda semana após o parto, estão associados a alto risco de deslocamento de abomaso e metrite (DUFFIELD et al., 2009).

Quadro 1. Importantes associações entre Acidos Graxos Não Extratiticados (AGNE) e betahidroxibutirato (BHBA) com saúde e desempenho emvacas no período de transição

\begin{tabular}{|c|c|}
\hline $\begin{array}{l}\text { Altas concentrações de AGNE }(>0,4 \mathrm{mmol} / \mathrm{L}) \\
\text { nas duas semanas antes do parto são associadas } \\
\text { a: }\end{array}$ & $\begin{array}{l}.400 \\
\text { ada a: }\end{array}$ \\
\hline $\begin{array}{l}\text { Aumento de } 2 \text { a } 4 \text { vezes no risco de deslocamento } \\
\text { de abomaso para a esquerda (LEBLANC et al., } \\
\text { 2005). } \\
\text { Aumento de } 1,8 \text { vezes no risco de retenção de } \\
\text { placenta (LEBLANC et al. 2005). }\end{array}$ & $\begin{array}{l}\text { Aumento de } 3 \text { a } 8 \text { vezes no risco de } \\
\text { deslocamento de abomaso (LEBLANC et al. } \\
\text { 2005; DUFFIELD et al. 2009). } \\
\text { Diminuição da probabilidade de prenhez a } \\
\text { primeira IA (GARVERICK et al., 2013). }\end{array}$ \\
\hline $\begin{array}{l}\text { Aumento de } 2 \text { vezes no risco de descarte antes dos } \\
60 \text { dias de lactação e } 1,5 \text { vezes no risco de } \\
\text { descarte durante toda a lactação (DUFFIELD et al. } \\
\text { 2009). }\end{array}$ & • ão da produção de leite (DUFFIELD et \\
\hline & $\begin{array}{l}\mathrm{Au} \\
\mathrm{ma}\end{array}$ \\
\hline
\end{tabular}

Adaptado de Rabelo et al (2009).

\section{ENFERMIDADES NO PERÍODO DE TRANSIÇÃO}

\section{Esteatose Hepática}

O período de transição de vacas leiteiras é marcado pelo BEN, onde mobiliza AGNE e acumula triglicerídeos no fígado (GRUMMER, 2005). Sob condições normais o fígado metaboliza todo AGNE que chega até ele que podem sofrer oxidação nas mitocôndrias ou serem esterificados nos hepatócitos em triglicerídeos, sendo transformados em fosfolipídios e colesterol, e levados para a corrente sanguínea na forma de lipoproteína de muito baixa densidade (VLDL), fornecendo energia imediata aos tecidos (ORTOLANI, 2009). Em determinado momento, quando a gordura que chega ao fígado excede a capacidade de oxidação ou transporte, o fígado não consegue aumentar a produção de VLDL, acumulando gordura que resulta em esteatose hepática (BEEVER, 2006). Vale ressaltar que os ruminantes possuem taxa lenta de exportação de AGNE na forma de VLDL, contribuindo assim para o acúmulo de gordura no fígado (GRUMMER, 1995). As perdas econômicas com a esteatose hepática remetem a gastos com tratamento e perdas de produção de aproximadamente 60 a 300 litros de leite por lactação, seguidos de perdas com a infertilidade e surgimento de outras doenças no periparto (BOBE et al., 2004). Conforme os 
estudos de Kim e Suh (2003) a taxa de incidência de cetose primaria correlacionada com a esteatose hepática é de $4,8 \%$.

As formas de prevenção da doença envolvem alimentação com níveis nutricionais adequados, uso de doses baixas de insulina de liberação lenta nos primeiros dias pós-parto e injeções de glicocorticoides. Nafikovetal (2006) relata que animais que receberam injeções subcutâneas de glucagon com dose de $15 \mathrm{mg} / \mathrm{dia}$ durante 14 dias, com início do tratamento a partir do segundo dia pós-parto, obtiveram eficácia na prevenção desta doença.

\section{Cetose}

A vaca leiteira no período de transição para atender a demanda de energia, acaba por mobilizar suas reservas de energia corporais, como a gordura (lipólise), elevando a produção de corpos cetônicos (OVERTON; WALDRON, 2004). Com o início da lactação, ocorre quadros de hipoglicemia para síntese da lactose do leite, estimulando a mobilização de ácidos graxos no tecido adiposo, ocorrendo a oxidação de ácidos graxos que vão ser metabolizados no fígado. Estes mesmos ácidos vão se acumular no fígado na forma de acetil-CoA, onde o excesso desta enzima será convertido em cetonas, acetoacetato e $\beta$-hidroxibutirato e acetona, estes por sua vez são metabolizados por vários tecidos e músculos (OSPINA, 2010). Um quadro clínico ou subclínico de cetose se forma quando a produção de corpos cetônicos ultrapassa a capacidade de uso pelos tecidos e músculos, havendo acúmulo de acetil-Coa no fígado (SORDILLO, 2013).

A elevada concentração de corpos cetônicos na circulação sanguínea, mas com ausência de sinais clínicos é configurada como cetose subclínica (IWERSEN et al., 2009), embora Fonseca et al. (2003) tenha relato ocorrência de baixa produção de leite e decréscimo nos níveis plasmáticos de glicose. A cetose clinica é configurada, por redução de ingestão de alimento e queda na produção de leite de 10 a 40\%. Em quadros mais evidentes de cetose, ocorrem perdas de peso, letargia e hiperexcitabilidade, hálito cetônico característico, hipoglicemia, hipoinsulinemia, com elevados níveis de ácidos graxos livres na circulação sanguínea, levando o animal a morte em alguns casos (STER, 2012). Quadros de cetose clínica e subclínica resultam em perdas econômicas, devido a redução da produção leiteira, problemas reprodutivos e elevação do risco de deslocamento de abomaso (IWERSEN et al., 2009). Walsh et al. (2007) realizaram estudo onde constataram redução de $50 \%$ na probabilidade de vacas emprenharem, quando tiveram quadro anterior de cetose subclínica.

O tratamento da cetose é realizado com glicose, corticosteroides e substâncias precursoras da glicose como glicerina e propilenoglicol (ORTOLANI, 2009), outros autores afirmam que o correto manejo nutricional reduz a incidência de cetose (OVERTON; WALDRON, 2004). 


\section{Hipocalcemia}

A hipocalcemia é doença metabólica nutricional, também é conhecida como febre do leite, ou síndrome da vaca caída, muito comum de ocorrer em vacas leiteiras de grande produção (ROCHE, 2006). A ocorrência desta doença está ligada ao acelerado decréscimo do íon cálcio $\left(\mathrm{Ca}^{++}\right)$do plasma, devido à grande mobilização do mesmo para a síntese do leite (incluindo colostro) e também por causar fraqueza muscular (CORASSIN, 2004). Três fatores que afetam a homeostasia do cálcio podem justificar estes sintomas, onde o primeiro é a excessiva perda de cálcio no colostro e das concentrações do mesmo no volume de leite produzido; o segundo fator é a existência da redução da absorção de cálcio pelo intestino no momento do parto; o terceiro e mais importante, é que a mobilização do cálcio do seu estoque no esqueleto não é rápida o suficiente para manter normais os níveis séricos (FRANÇA, 2013).

No final da gestação as taxas de mobilização do $\mathrm{Ca}^{++}$e suas reservas estão reduzidas para repor de maneira satisfatória e rápida as perdas ocorridas na produção de leite. A idade da vaca, aumenta a incidência de hipocalcemia, este fato ocorre devido à redução da absorção de cálcio dos alimentos conforme o animal envelhece, e também está relacionado a queda de seus níveis plasmáticos (HORST, 2004). As perdas de $\mathrm{Ca}^{++}$durante o período de transição registram 5-7 $\mathrm{g} / \mathrm{dia}$ de $\mathrm{Ca}^{++}$para o feto nos últimos dois meses antes do parto, com aumento de 15-20 g/dia ${ }^{-1}$ na secreção do colostro e produção de leite (concentração de $\mathrm{Ca}^{++}$no colostro $2,2 \mathrm{~g} / \mathrm{L}^{-1}$; concentração de $\mathrm{Ca}^{++}$no leite $1,3 \mathrm{~g} / \mathrm{L}^{-1}$ ). Quanto as perdas urinarias e fecais de $\mathrm{Ca}^{++}$, para manter o "pool" de (70-80 g/dia $\left.{ }^{-1}\right)$ é necessário maior absorção a nível intestinal ou aumento da reabsorção óssea (REINHARDT et al., 2011).

De acordo com Ortolani, (2009), a ocorrência da hipocalcemia se dá em três fases distintas, sendo a primeira caracterizada por um animal consciente e com sinais de excitação, tetania, ataxia, rigidez dos membros posteriores, aspecto de cavalete, com quedas e hipertermia, que pode durar de 40 minutos a oito horas. Na segunda fase, a vaca reduz os reflexos e a sensibilidade cutânea, apresentando taquicardia, diminuição dos movimentos ruminais, constipação, evoluindo para quadro de vaca caída. Na fase final, existe perda da consciência com decúbito lateral, atonia ruminal, levando o animal a óbito por insuficiência cardiorrespiratória ou por compressão do diafragma.

A imunidade de vacas hipocalcêmicas reduz devido aos altos níveis de cortisol, onde acabam tendo predisposição a outras doenças como a mastite, retenção de membranas fetais, involução uterina, metrite, deslocamento de abomaso e cetose (GOFF, 2008), conforme figura 2. 
Figura 2- Predisposição de eventos em um quadro de hipocalcemia.

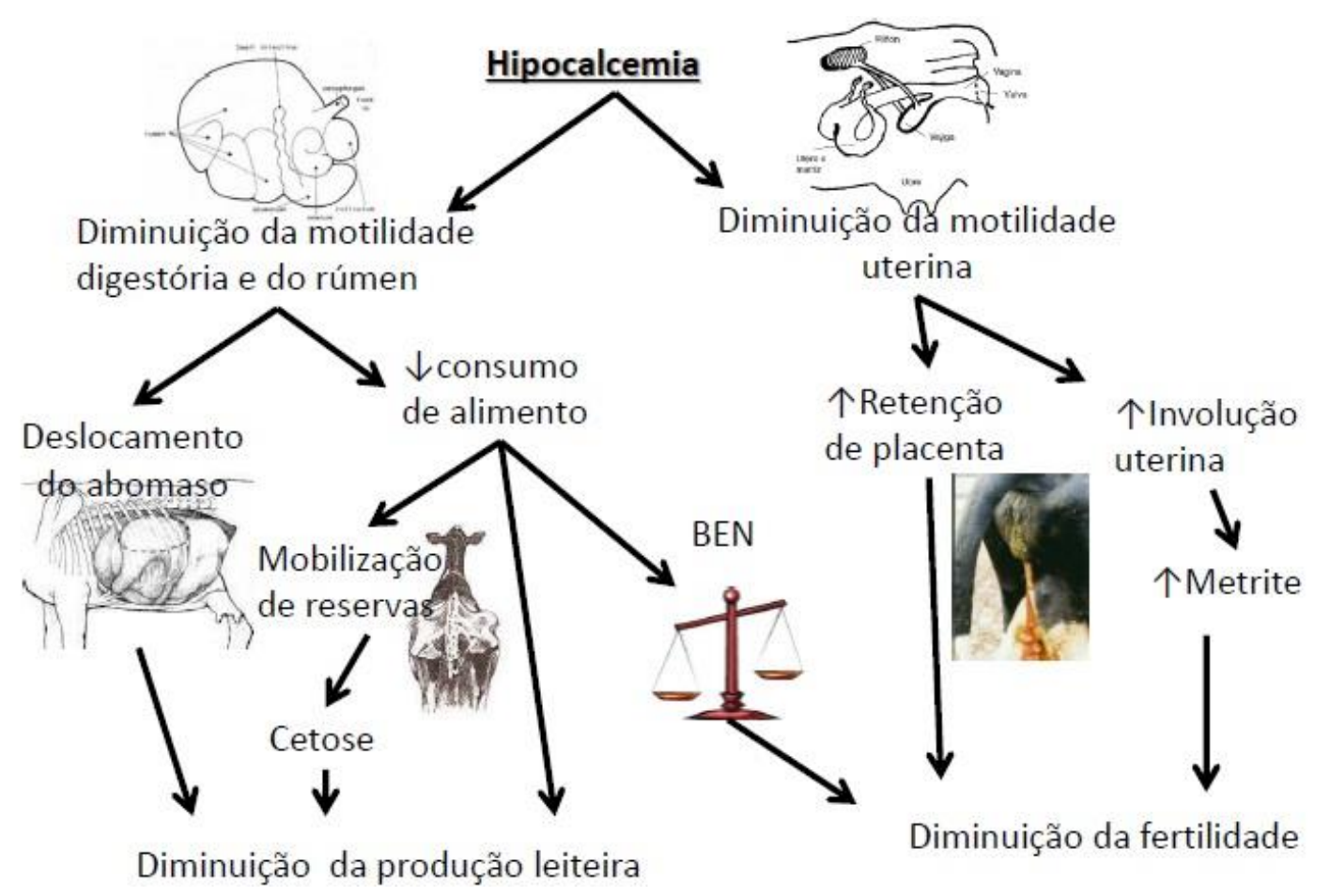

Adaptado de Goff, (2008).

Segundo Oetzel (2013) o tratamento para a hipocalcemia a base de $\mathrm{Ca}^{++}$é eficaz na primeira e segunda fase da doença, mas tem baixos resultados na terceira, resultando em sérias perdas econômicas devido ao aumento de incidência de outras doenças como involução uterina, retenção de placenta, metrite, redução da fertilidade.

\section{Acidose Ruminal}

Esta doença metabólica envolve basicamente a composição da dieta do animal, que será a determinante para desencadear uma série de acontecimentos a nível ruminal nos animais (SCHWARTZKOPF-GENSWEIN et al., 2004). No período seco as vacas recebem maior quantidade de alimentos volumosos com maior quantidade de fibra e menos alimentos concentrados, normalmente por motivos econômicos (ORTOLANI, 2009). Logo após o parto, o animal lactante precisa de dieta com mais energia para a produção de leite, e os concentrados, agora em maior porção, voltam a ser incluídos na dieta sem uma adaptação de aumento gradativo, fazendo com que esta mudança brusca na alimentação leve o animal a desenvolver acidose ruminal, que pode ser dividida em Acidose Láctica Ruminal Aguda - ALRA (causada pelo excesso de ácido láctico) e Acidose Ruminal Subaguda - ARS (causada pelos ácidos graxos voláteis) (KRAUSE; OETZEL, 2006). 
A ALRA é desenvolvida pela ingestão em excesso de carboidratos fermentáveis, resultando em queda brusca de $\mathrm{pH}$ ruminal, aumentando as concentrações de ácido lático. $\mathrm{O}$ erro de manejo, em não adaptar os animais gradualmente a nova dieta, com maior concentração de energia, desenvolve a ALRA, já que a população de bactérias viáveis conversoras de ácido lático (principalmente Megasphaera elsdenii e Selenomonas ruminantium), tem suas papilas ruminais curtas e sem capacidade de absorção de altas quantidades de ácidos graxos voláteis (WALSH et al. 2007). Na ARS, o pH cai moderadamente (5,5- 5,0), devido ao acúmulo de ácidos graxos voláteis e não tem presença de acúmulo de ácido lático nesta fase, que geralmente compreende o período entre o parto e cinco meses após (OETZEL, 2006). Para ALRA, os animais apresentam anorexia, cambaleio, desidratação, atonia ruminal, rúmen cheio de liquido, diarreia, taquicardia, podendo apresentar febre em caso de peritonite, abscesso hepático, como outras infecções secundárias e timpanismo crônico (RADOSTITS et al., 2000).

A prevenção da acidose ruminal, se dá através do tamponamento ruminal por tampões endógenos ou dietéticos na dieta, com quantidades adequadas de cátion em relação a ânions, e correta relação de volumoso:concentrado, que garanta níveis de fibra para perfeito funcionamento ruminal e concentrado para manter a energia necessária na dieta, afim de atender as exigências destes animais neste período de transição (RABELO, 2009).

\section{Deslocamento de abomaso}

Deslocamento de abomaso atinge cerca de 5\% das vacas em lactação, e em 90\% dos casos ocorre até seis semanas pós-parto, em que a prevalência desta doença varia de rebanho para rebanho dependendo da localização geográfica, práticas de manejo, clima, entre outros fatores, sendo que os prejuízos incluem custos de tratamento, queda de produção de leite, descarte de leite, efeitos negativos sobre a reprodução, descarte prematuro de animais e mortes (VAN WINDEN et al., 2003).

De acordo com Raizman e Santos (2002) o deslocamento de abomaso para a esquerda, é uma condição em que o abomaso fica repleto de fluído e gases decorrente da fermentação microbiana que distende o abomaso, devido a altos teores de concentrado na dieta, que acaba por reduzir a motilidade abomasal. Outros fatores que levam a predisposição para deslocamento de abomaso, podem estar ligados a distocia, parição gemelar, retenção de placenta, metrite, hipocalcemia, fígado gorduroso e cetose (SARASHINA, 1991). No caso da hipocalcemia, os baixos níveis de $\mathrm{Ca}^{++}$afetam a motilidade do abomaso, que em quantidades normais é 1,2 mmol/ $\mathrm{L}^{-1}$, e abaixo deste valor não existe motilidade (OETZEL, 2013). O deslocamento de abomaso não prejudica as taxas de concepção, mas o período do parto ao primeiro serviço é maior (CAMARA et al., 2010). 


\section{ENFERMIDADES UTERINAS}

\section{Retenção de Placenta}

Doenças que afetam o trato reprodutivo da vaca no pós-parto, elevam os custos com tratamentos, aumentam o descarte de fêmeas que apresentam repetidas falhas na concepção e a necessidade de reposição de outros animais no plantel para compensar as perdas de produção (SHELDON et al., 2009).

A retenção de placenta (RP) é problema que persiste significativamente em propriedades leiteiras, apresentada como falha na separação das vilosidades da placenta fetal (cotilédones) com as criptas maternas (carúnculas), onde a placenta permanece aderida ao útero após 12 horas da expulsão do feto (FERREIRA, 2010). A RP é multifatorial, nos quais temos fatores mecânicos ligados a problemas no parto como distocia, parto gemelar, natimorto, parto induzido, aborto, deficiências nutricionais e redução da imunidade devido a processos infecciosos como a endometrite (GUNAY et al., 2011).

A eficiência reprodutiva cai bruscamente quando estas enfermidades uterinas se instalam, pois, vacas com RP reduzem $15 \%$ sua taxa de prenhez, quando comparadas a vacas sadias (FOURICHON et al., 2000), enquanto que vacas com endometrite podem chegar a $50 \%$ a taxa de concepção (KASI-MANICKAM et al., 2004). Resumo de consequências reprodutivas oriundas das doenças metabólicas pode ser observado no quadro 2.

Quadro 2 - Consequências reprodutivas das doenças metabólicas.

\begin{tabular}{|c|c|c|}
\hline $\begin{array}{c}\text { Doenças } \\
\text { metabólicas }\end{array}$ & Alterações metabólicas & Efeito na reprodução \\
\hline $\begin{array}{l}\text { Esteatose } \\
\text { Hepática }\end{array}$ & $\begin{array}{l}\text { Diminuição da síntese de colesterol e albumina e } \\
\text { de liberação de glicose, acúmulo de amônia e } \\
\text { consequente baixa liberação de insulina e IGF-I. }\end{array}$ & $\begin{array}{llcc}\text { Atraso na } & \text { ovulação, no estro } & \text { e no } \\
\text { primeiro } & \text { serviço. } & \text { Prejuízo } & \text { no } \\
\text { desenvolvimento embrionário } & \end{array}$ \\
\hline Cetose & $\begin{array}{l}\text { Hipoglicemia, diminuição da pulsatilidade de LH, } \\
\text { acúmulo de corpos cetônicos, baixa liberação de } \\
\text { insulina e IGF-I. }\end{array}$ & $\begin{array}{l}\text { Atraso na ovulação, queda das taxas de } \\
\text { concepção ao primeiro serviço, } \\
\text { prolongados intervalos entre parto e } \\
\text { concepção e prejuízo } \\
\text { desenvolvimento embrionário. }\end{array}$ \\
\hline $\begin{array}{l}\text { Deslocamento } \\
\text { abomasal }\end{array}$ & $\begin{array}{l}\text { Hipocalcemia, elevadas concentrações de corpos } \\
\text { cetônicos e ácidos graxos não esterificados. }\end{array}$ & $\begin{array}{l}\text { Prolongado período do parto ao primeiro } \\
\text { serviço. }\end{array}$ \\
\hline Hipocalcemia & \begin{tabular}{llll} 
Diminuição & da contratilidade & \multicolumn{2}{c}{ uterina. } \\
Predisposição à lipidose hepática, cetose e & à \\
deslocamento & abomasal; baixa liberação de \\
insulina.
\end{tabular} & $\begin{array}{l}\text { Distocia, retenção de placenta, } \\
\text { Endometrite, anestro, reduzidas taxas de } \\
\text { concepção para inseminação artificial. } \\
\text { Prejuízo no desenvolvimento } \\
\text { embrionário }\end{array}$ \\
\hline
\end{tabular}

Adaptado de Schütz (2007). 
Selênio e Vitamina E, vem sendo utilizados por várias décadas como alternativas para melhorar o sistema imunológico de vacas leiteiras. O Selênio possui enzima glutationaperoxidase (GT-P) que atua no sistema imunológico do animal e participa de respostas imunes específicas do aparelho reprodutor e glândula mamária. O selênio também trabalha em conjunto com a vitamina E para manter a integridade celular e melhorar a resposta imune. Com correta suplementação de selênio e vitamina E para vacas e novilhas prenhes, reduz a incidência de retenção de placenta, infecções uterinas e mastite clínica no início da lactação. Resultados de estudo realizado por Collet (2018), com vacas leiteiras usando Se e vit E pode ser observado na Tabela 3.

Tabela 3- Uso de Selênio e vitamina E na frequência (\%)de enfermidades reprodutivas de vacas leiteiras

\begin{tabular}{lccc}
\hline \multicolumn{1}{c}{ Suplementação } & Retenção de Placenta & Metrite & Ovário Cístico \\
\hline Se + Vit E & $0 \mathrm{a}$ & $57 \mathrm{a}$ & $19 \mathrm{a}$ \\
Vit E & $20 \mathrm{~b}$ & $84 \mathrm{~b}$ & $44 \mathrm{~b}$ \\
Selênio & $17 \mathrm{~b}$ & $65 \mathrm{a}$ & $19 \mathrm{a}$ \\
Controle & $16 \mathrm{~b}$ & $83 \mathrm{~b}$ & $50 \mathrm{~b}$ \\
\hline & Adaptado de Harrison (1984).
\end{tabular}

A incidência de retenção de placenta foi zero, metrite e ovário cístico reduziram consideravelmente com uso deSe + vit E quando comparados ao grupo controle.

\section{MANEJO NUTRICIONAL DURANTE O PERÍODO DE TRANSIÇÃO}

\section{Uso de Aditivos na Dieta}

O intuito da utilização de aditivos na dieta de vacas leiteiras no período de transição é proporcionar melhoria dos padrões de fermentação ruminal, otimizar a digestão de carboidratos fibrosos, reduzir a mobilização de reservas corporais e obter diminuição de distúrbios do metabolismo intermediário (BOWERS et al., 2006). O produtor precisa estar ciente que nenhum aditivo substituirá ou corrigirá falhas de manejo e de dietas desbalanceadas, outra questão é o fator econômico, em que a resposta animal frente ao uso destes produtos precisa ser superior aos custos de utilização.

\section{Sais aniônicos}

A utilização do conceito de balanço cátion-aniônico nas dietas de vacas de alta produção durante o período de transição é devido a influência que esse balanço pode ter nos níveis séricos de cálcio, pré e pós-parto e no desempenho animal (WEICH, 2013). O balanço cátion-aniônico é 
a relação entre a concentração em miliequivalentes $(\mathrm{mEq})$ de cátions (minerais com cargas positivas) e ânions (minerais com cargas negativas) nos fluidos corporais. Esse conceito assume que o influxo de qualquer íon aos fluidos corporais é capaz de alterar o balanço ácido-básico do organismo (HORST et al., 1997). A dieta aniônica consiste na adição de sais aniônicos com base em sulfatos e cloretos para negativar o balanço cátion-aniônico da dieta (DCAD), é uma estratégia na prevenção da hipocalcemia. Dietas com níveis altos de sódio e potássio resultam em alcalose metabólica (GOFF et al., 2004), devido a isso, as vacas no pré-parto têm a habilidade de manter a homeostase de cálcio comprometida por reduzir a responsividade do tecido ao paratohormônio (PTH) (GOFF; HORST, 1997). Ao comprometer os níveis séricos do $\mathrm{Ca}^{++}$, um quadro de hipocalcemia vai se instalar, mantendo baixos níveis de $\mathrm{Ca}^{++}$a capacidade de contração muscular diminui ocorrendo imunossupressão, retardando a motilidade do trato digestivo e reprodutivo, tendo como consequência vacas com retenção de placenta, metrite, deslocamento de abomaso e mastite.

\section{Ionóforos (monensina sódica)}

Ionóforos são aditivos que trazem bons resultados na inclusão da dieta de vacas leiteiras, pois são antibióticos que atuam em algumas bactérias do trato ruminal, inibindo as grampositivas, protozoários e fungos, favorecendo o desenvolvimento das gram-negativas (GANDRA et al., 2010). Desta maneira o efeito destas mudanças na flora bacteriana é um incremento da produção de propionato e redução na produção de acetato e butirato, promovendo mais precursores glicogênicos, além de diminuir a gordura no leite, evitando maiores perdas energéticas (OLIVEIRA et al., 2005).

A monensina sódica é um ionóforo aprovado e utilizado para vacas leiteiras em alguns países como Austrália, Argentina, Canadá, Brasil, Nova Zelândia, África do Sul, e Estados Unidos. A monensina é um poliéter carboxílico, produzido a partir do fungo Streptomyces cinnamonensis (BAGG, 2008), que altera o fluxo dos íons monovalentes pela membrana das bactérias gram-negativas, alterando sua função normal e causando o rompimento destes microorganismos (DUFFIELD et al., 2008).

O período de lactação dos animais é o fator que tem maior influência sobre a resposta a suplementação com monensina sódica em vacas leiteiras. Segundo relatos de Clark (2003), a monensina demonstra uma redução no BHB plasmático e uma menor prevalência de cetose clínica, devido ao aumento da síntese hepática de glicose, que melhora o balanço de energia, com consequente aumento na produção de leite.

A dose de utilização de monensina em qualquer período da lactação submetidas a qualquer tipo de volumoso é feita com 16 mg.kg $\mathrm{MS}^{-1}$ ou $2924 \mathrm{mg} . \mathrm{kg} \mathrm{MS}^{-1}$, sendo esta última 
forma utilizada para animais em produção, e a primeira em animais em crescimento ou em período de transição (DUFFIELD et al., 2008). Ultrapassar essas doses não é recomendado, devido a propensão em causar queda de desempenho produtivo e intoxicações (PLAIZER et al., 2000). Nos estudos de Bagg et al. (2008) com doses de monensina de 72, 144 e 240 mg.kg MS ${ }^{-1}$ em rações de vacas no início de lactação, houve redução de $61,7 \%$ e 23,7\% na IMS e produção de leite, respectivamente, e após a terceira aplicação, na dose de $240 \mathrm{mg} . \mathrm{kg} \mathrm{MS}^{-1}$, houve sinais de intoxicação.

\section{Extrato de Levedura (Saccharomyces cerevisiae)}

A utilização de levedura na dieta de vacas leiteiras altera a fermentação ruminal, estimulando o crescimento microbiano no rúmen e favorecendo a digestão da fibra, melhorando a IMS e aumentando a produção de leite (BITENCOURT et al., 2008). Nos trabalhos de Williams et al. (1991) foi observado que a suplementação de vacas em estádio intermediário da lactação com $10 \mathrm{~g}$ de levedura, obteve um aumento no consumo diário de matéria seca em 1,2 kg.

Dann et al. (2000) também observaram um aumento de 2,1 kg no consumo nos sete últimos dias de gestação e de 1,6 kg nos primeiros 42 dias da lactação quando suplementaram leveduras para vacas leiteiras no período de transição. Um possível mecanismo para o maior consumo quando se suplementa leveduras seria por indução de ganho em digestão da fibra (BITENCOURT et al., 2008).

\section{NOVAS TÉCNICAS PARA REDUZIR OS DISTÚRBIOS METABÓLICOS}

\section{-Inibição da Síntese da Gordura do Leite com uso de Ácido Linoleico Conjugado (CLA)}

A gordura do leite é o componente que mais demanda energia do animal para sintetizar, representando cerca de $50 \%$ da energia total. Reduzir esse teor de gordura durante o período pósparto é visto como uma estratégia para melhorar o balanço de energia durante o período de transição (SELBERG et al., 2004).

De maneira usual, uma dieta rica em concentrado e pobre em fibras causaria a depressão da gordura do leite (DGL), mas no período de transição tal dieta seria prejudicial à saúde da vaca (BERNAL-SANTOS et al., 2003). A DGL pode ser induzida de uma forma totalmente segura através de uma dieta com adição de ácidos graxos, com gordura protegida da ação ruminal, como adição de óleo de peixe-trans- 10 (Lacasse et al., 2002) ou, ácido linoleico conjugado (CLA) cis 12 (Baumgard et al.,2000). De acordo com Harvatine et al. (2009) ambos os suplementos lipídicos deprimem a síntese de gordura do leite através da inibição do gene de enzimas 
lipogênicas, enquanto o óleo de peixe também deprime o teor de proteína do leite e o consumo de ração, o CLA parece ter poucos efeitos secundários e prejudiciais ao animal.

Ao testar o uso de CLA durante o período de transição, Sigl et al. (2010) verificaram que as doses de CLA foram insuficientes para deprimir a gordura do leite imediatamente a pós o parto. Quando uma dose mais elevada foi utilizada, notaram que na primeira semana de lactação já houve depressão da gordura do leite, sendo crescente na segunda e terceira semana da lactação (SCHÄFERS et al., 2017).

Foi relatado por Kay et al. (2006) e Odens et al. (2007) uma redução nos índices de AGNE no sangue, melhorando o balanço energético negativo. Nenhum efeito positivo com uso de CLA na alimentação de vacas em período de transição foi relatado no estudo de Petzold et al. (2015), no entanto o teor de gordura do leite não foi inibido neste estudo. Dois estudos realizados por Chandler et al. (2017) e Hutchinson et al. (2012), a redução na gordura do leite foi compensada por um aumento da produção de leite, o que resulta em nenhuma redução da produção de energia de leite.

De maneira geral, parece que a alimentação de CLA-protegido no rúmen pode ser uma estratégia útil para aumentar a produção de leite e rendimento proteico durante a lactação estabelecida.

\section{-Ordenha no Pré-Parto}

Vem sendo estudada desde os anos 1940 (BAREILLE, 1996) a hipótese que a prática de ordenhar vacas antes do parto poderia prevenir perturbações metabólicas, aumentar a absorção de AGNE pela glândula mamária evitando assim a redução da IMS em torno do parto. Na maioria dos estudos, as vacas foram ordenhadas duas vezes por dia durante as últimas duas ou três semanas antes da data do parto (RASTANI et al., 2007).

Embora alguns estudos relataram maior produção de leite no início período pós-parto, a maioria não relatou um aumento na produção de leite para além deste período (DANIELS et al., 2007). Outro fator negativo com essa indução a lactogênese, seria a redução da qualidade do colostro, pois reduz a concentração de imunoglobulinas (GUY et al., 1994).

Como hipótese a ordenha no pré-parto aumenta a IMS, no entanto, este aumento não é suficiente para compensar a maior exigência de energia para todo a síntese do leite e faz com que o balanço energético negativo se agrave (RASTANI et al., 2007). Ao analisar o soro de vacas ordenhadas no pré-parto, Grummer et al. (2000) relataram níveis baixos de glicose no sangue após o parto e Santos et al. (2004) relataram maiores concentrações de AGNE BHB antes do parto, bem como uma maior concentração BHB no início do período pós-parto. 
Em contrapartida, alguns estudos relataram efeitos positivos sobre a incidência de doenças metabólicas e infecciosas em vacas ordenhadas no pré-parto. Santos et al (2004) relataram redução nos casos de febre do leite e cetose subclínica, assim como a saúde da glândula mamária apresentou melhora diminuindo os casos de edema de úbere, contagem de células somáticas e infecções intramamária durante o período pós-parto.

Avaliando como um todo, a técnica de ordenha pré-parto apresenta benefícios limitados e parece não ser suficiente para compensar o custo adicional deste manejo e a perda da qualidade do colostro.

\section{-Ordenha Uma Vez ao Dia}

Uma forma de limitar a produção de leite durante o período de transição é reduzir o número de ordenhas diárias, se limitando em apenas uma (PHYN et al, 2014). Alguns estudos avaliaram o efeito de ordenha uma vez ao dia logo após o parto até 7 semanas seguintes, avaliando produção de leite, balanço energético negativo e concentrações metabólicas no sangue. Em todos os estudos, ordenhar vacas uma vez ao dia reduziu a produção de leite, melhorou o balanço energético negativo e ocasionou menor perda de peso corporal dos animais (O'DRISCOLL et al., 2012).

Por conseguinte, uma ordenha diária melhora a glicemia pós-parto e reduz o aumento no sangue de AGNE, sendo que apenas três estudos relataram concentração de BHB no sangue. Já Schlamberger et al. (2010) relataram uma diminuição significativa de BHB. Uma grande desvantagem de ordenhar uma vez ao dia durante várias semanas é que ela reduz a quantidade de leite (MCNAMARA et al., 2008).

Conforme os estudos de Loiselle et al. (2009), em que vacas foram ordenhas uma vez ao dia no período de uma semana, produziram $31 \%$ menos de leite que vacas ordenhadas duas vezes ao dia. Nas 13 semanas seguintes de lactação, a produção de leite de vacas de uma ordenha diária foi $8 \%$ inferior à de vacas com duas ordenhas diárias. No entanto as percentagens de gordura e proteína foram maiores no leite das vacas ordenhadas uma vez ao dia, os rendimentos destes componentes do leite corrigido para energia foram similares entre os dois grupos de vacas (O'DRISCOLL et al., 2012). Além disso os aumentos das concentrações no sangue de AGNE e BHB foram maiores para vacas com duas ordenhas diárias, enquanto que a concentração de glicose no plasma foi maior para vacas com uma ordenha diária (LOISELLE et al., 2009). As diferenças entre os dois grupos persistiram até o $24^{\circ}$ dia para concentrações de AGNE e glicose, e até o $14^{\circ}$ dia para BHB (STER et al., 2012). 
Portanto, o efeito é positivo se limitar a ordenha em uma vez ao dia para a primeira semana de lactação, pois reduz as concentrações dos metabólitos e diminui as perdas com a produção de leite.

\section{-Ordenha Incompleta}

No ato da ordenha são liberados oxitocina, prolactina e glicocorticoides no sangue na vaca lactante (LACASSE; OLLIER, 2014). A concentração basal e liberação de prolactina no momento da ordenha está relacionada com o nível produção de leite (LACASSE et al., 2016).

Carbonneau et al. (2012) conduziram experimento para testar a hipótese de que reduzindo a produção de leite por meio de ordenha incompleta, enquanto se mantém o estímulo de remoção frequente do leite, melhora o estado metabólico e funções imunitárias, sem afetar a produção de leite subsequente.

Num experimento conduzido com vacas de alta produção, ordenhadas sem a retirada total do leite duas vezes por dia até o $5^{\circ}$ dia após o parto, durante o período de tratamento, a produção de leite média foi de 27,3 kg.leite.dia ${ }^{-1}$ para as vacas do grupo controle e 9,7 kg.leite.dia ${ }^{-1}$ para as vacas ordenhadas incompletamente. Como resultado, a diminuição da produção de leite através de ordenha incompleta resultou em maior concentração de glicose no sangue e menores concentrações de AGNE e BHB (KRUG et al., 2017). O impacto de ordenha incompleta, é, possivelmente, associado a aumento da pressão intramamária (OLLIER et al., 2014).

Estudo realizado em 813 laticínios com vacas multíparas de 13 rebanhos diferentes, onde foram distribuídas em grupos para ordenha incompleta (10 a 14 kg.leite.dia ${ }^{-1}$ ) durante 5 dias e grupos para ordenha completa. $\mathrm{O}$ grupo de ordenha incompleta produziu metade do leite quando comparado ao grupo de ordenha completa, mas logo após o período do experimento a produção de leite corrigido para energia foi semelhante para ambos os grupos (KRUG et al., 2017). O grupo de vacas com ordenha incompleta reduziu a concentração de BHB no sangue, diminuindo a prevalência de cetose e problemas inflamatórios (MORIN et al., 2016). Esses resultados sugerem que a ordenha incompleta é uma maneira eficaz de reduzir o balanço energético negativo em vacas leiteiras, mas uma análise mais aprofundada dos dados deve indicar se esta abordagem resulta em menor incidência de doenças metabólicas.

\section{CONCLUSÃO}

O período de transição é caracterizado pelo desenvolvimento de diversas doenças metabólicas devido a desiquilíbrios energéticos, redução de produção de leite, resultando em graves perdas econômicas. 
O aumento dos níveis no sangue de AGNE e BHB prejudicam as funções metabólicas no pré e pós-parto, como também nas reproduções futuras.

O uso de aditivos é uma alternativa eficaz na prevenção de doenças metabólicas e como incremento na IMS, mas precisa ser associado a dieta com planejamento e manejo correto para ter a reposta animal esperada e evitar perdas.

Entre as técnicas para reduzir as disfunções metabólicas e de imunossupressão durante o período de transição, limitar a produção de leite durante a primeira semana de lactação com ordenha incompleta duas vezes ao dia é o mais indicado, pois reduz o balanço energético negativo, consequentemente os níveis de AGNE e BHB no sangue caem, não comprometendo o resto da lactação, além disso é uma estratégia que não envolve custos adicionais ou uso de medicamentos sendo economicamente justificada.

\section{REFERÊNCIAS}

ADEWUYI, A. A.; GRUYS, E.; VAN EERDENBURG, F. J. C. M. Non esterified fatty acids (NEFA) in dairy cattle. A review. Veterinary Quarterly, v. 27, n.3, p.117-126, 2005.https://doi.org/10.1080/01652176.2005.9695192

ARAÚJO, C. A. S. C. Estudo comparativo do perfil metabólico e hormonal de ovelhas com gestação única, gemelar e não gestantes alimentadas com dieta de alta densidade energética, 2009. 212 f. Dissertação (Mestrado em Medicina Veterinária) - Faculdade de Medicina Veterinária e Zootecnia, Universidade de São Paulo, São Paulo, 2009.

BAUMGARD, L. H.et al. Identification of the conjugated linoleic acid isomer that inhibits milk fat synthesis. American Journal of Physiology-Regulatory, Integrative and Comparative Physiology, v. 278, p. R179-R184, 2000.

BAUMGARD, L. H.; ODENS, L. J.; KAY, J. K. Does Negative Energy Balance (NEBAL) Limit Milk Synthesis in Early Lactation? In: 21ST ANNUAL SOUTHWEST NUTRITION \& MANAGEMENT CONFERENCE, 2006, Tempe. Proceedings. Tempe, Arizona: University of Arizona, 2006. p. 23-24.

BAGG, R.et al. Milk residues and performance of lactating dairy cows administered high doses of monensin. The Canadian Journal of Veterinary Research, v. 69, p. 180-185, 2005.

BAREILLE, N.; FAVERDIN, P. Lipid Metabolism and Intake Behavior of Dairy Cows: Effects of Intravenous Lipid and $\beta$-Adrenergic Supplementation. Journal of Dairy Science, v.79, p.12091220, 1996. https://doi.org/10.3168/jds.S0022-0302(96)76474-3

BEITZ, D. C. Digestão, absorção e metabolismo. In: Dukes fisiologia dos animais domésticos. 11. ed. Rio de Janeiro: Guanabara-Koogan, 1996.

BEEVER, D. E. The Impact of controlled nutrition during the Dry Period on Dairy Cow Health, Fertility and Performance. Animal Reproduction Science, v. 96, p. 212-226, 2006.

https://doi.org/10.1016/j.anireprosci.2006.08.002 
BERNAL-SANTOS, G.et al. Production responses of dairy cows to dietary supplementation with conjugated linoleic acid (CLA) during the transition period and early lactation. Journal of Dairy Science, v. 86, p.3218-3228, 2003. https://doi.org/10.3168/jds.S0022-0302(03)73925-3

BITENCOURT, L. L.et al. Response of lactating cows to the supplementation with live yeast. Journal of Dairy Science, v. 91, W208, Suppl. 1, p. 264, 2008.

BOBE, G.; YOUNG, J. W.; BEITZ, D. C. Invited Review: Pathology, Etiology, Prevention, and Treatment of Fatty Liver in Dairy Cows. Journal of Dairy Science, v. 87, n. 10, p. 3105-3124, 2004.https://doi.org/10.3168/jds.S0022-0302(04)73446-3

BOWERS, S.et al. Effects of prepartum milking on postpartum reproduction, udder health and production performance in first-calf dairy heifers. Journal of Dairy Researcher, v. 73, p.257263, 2006. https://doi.org/10.1017/S0022029906001762

CÂMARA, A. C. L.et al Fatores de risco, achados clínicos, laboratoriais e avaliação terapêutica em 36 bovinos com deslocamento de abomaso. Pesquisa Veterinária Brasileira, v. 30, n.5, p.453-464, 2010.

CARBONNEAU, E.et al. The effect of incomplete milking or nursing on milk production, blood metabolites, and imune functions of dairy cows. Journal of Dairy Science, v. 95, p.6503-6512, 2012. https://doi.org/10.3168/jds.2012-5643

CARSON, M. The association of selected metabolites in peripartum dairy cattle with health and production. MSc dissertation. University of Guelph. 2008

CHANDLER, T. L.et al. Conjugated linoleic acid supplementation during the transition period increased milk production in primiparous and multiparous dairy cows. Animal Feed Science and Technology v. 224, p. 90-103, 2017. https://doi.org/10.1016/j.anifeedsci.2016.12.008

CHAPINAL, N.et al. The association of serum metabolites with clinical disease during the transition period. Journal of Dairy Science v. 94 p. 4897-4903, 2011.

https://doi.org/10.3168/jds.2010-4075

COLLET, S.G._Efeito do uso de Minerais Traços e Vitaminas A e E na Saúde de Vacas Holandesas no Período de Transição, 2018.70 f. Tese (Doutorado em Medicina Veterinária)Faculdade de Medicina Veterinária, Universidade Federal de Santa Maria, Santa Maria, 2018.

CONTRERAS, G. A.et al. Lipomobilization in periparturient dairy cows influences the composition of plasma non esterified fatty acids and leukocyte phospholipid fatty acids. Journal of Dairy Science, v. 93, p.2508-2516, 2010. https://doi.org/10.3168/jds.2009-2876

CORASSIN, C. H. Determinação e avaliação de fatores que afetam a produtividade de vacas leiteiras: Aspectos sanitários e reprodutivos. 2004. 113p. Tese (Doutorado em Agronomia) Escola Superior de Agricultura "Luiz de Queiroz", Universidade de São Paulo, Piracicaba, 2004.

DANN, H. M.et al. Effects of yeast culture (Saccharomyces cerevisiae) on prepartum intake and postpartum intake and milk production of Jersey cows. Journal of Dairy Science, v. 83, p. 123127, 2000. https://doi.org/10.3168/jds.S0022-0302(00)74863-6

DANIELS, K. J.et al. Prepartum milking of heifers influences future production and health. Journal of Dairy Science, v. 90, p. 2293-2301, 2007. https://doi.org/10.3168/jds.2005-881 
DRACKLEY, J. K. Biology of dairy cows during the transition period: the final frontier? Journal of Dairy Science, v. 82, n. 11, p. 2259-2273, 1999. https://doi.org/10.3168/jds.S0022$\underline{0302(99) 75474-3}$

DRACKLEY, J. K.et al. Physiological and pathological adaptations in dairy cows that may increase susceptibility to periparturient diseases and disorders. Italian Journal of Animal Science, v. 4, p.323-344, 2005. https://doi.org/10.4081/ijas.2005.323

DUFFIELD, T. F.; RABIEE, A. R.; LEAN, I. J. A meta-analysis of the impact of monensin in lactating dairy cattle. Part2. Production effects. Journal of Dairy Science, v. 91, p. 1347-1360, 2008. DOI: https://doi.org/10.3168/jds.2007-0608

DUFFIELD, T. F.; LEBLANC, S. J. Interpretation of serum metabolic parameters around the transition period. In: SOUTHWEST NUTRITION AND MANAGEMENT CONFERENCE, 27., 2009, Tempe, Arizona. Proceedings... Tempe, Arizona: University of Arizona/ Department of Animal Science, 2009. p.106-114.

EMBRAPA. Anuário do leite 2018. Embrapa Gado de Leite. Disponível em: https://www.embrapa.br/busca-de-publicacoes/-/publicacao/1094149/anuario-leite-2018indicadores-tendencias-e-oportunidades-para-quem-vive-no-setor-leiteiro. Acesso 26 abril de 2019.

FERREIRA, A. M. Reprodução da fêmea bovina: fisiologia aplicada e problemas mais comuns (causas e tratamentos). Editora Editar, Juiz de Fora, p.219-243, 2010.

FRIGGENS, N. C. Body lipid reserves and the reproductive cycle: towards a better understanding. Livestock Production Science, v. 83, n. 2-3, p. 219-236, 2003.

https://doi.org/10.1016/S0301-6226(03)00111-8

FRANÇA, R. C. Hipocalcemia subclínica na vaca leiteira. Dissertação de Mestrado. Universidade de Lisboa, Faculdade de Medicina Veterinária, Lisboa, 2013.

FONSECA, L. F. L.et al. Suplementação de propilenoglicol para vacas no período peri-parto: efeitos sobre incidência de cetose, produção leiteira, escore corporal e primeiro estro pós-parto. Acta Scientiarum Animal Sciences, v. 25, no. 1, p. 177-183, 2003. http://dx.doi.org/10.4025/actascianimsci.v25i1.2143

FOURICHON, C.; SEEGERS, H.; MALHER, X. Effects of disease on repro-duction in the dairy cow: a meta-analysis. Theriogenology, v. 53, n.9, p.1729-1759, 2000.

https://doi.org/10.1016/S0093-691X(00)00311-3

GANDRA, J. R. Productive performance and milk protein fraction composition of dairy cows supplemented with sodium monensin. Revista Brasileira de Zootecnia, v.39, n.8, p.1810-1817, 2010. http://dx.doi.org/10.1590/S1516-35982010000800025

GARVERICK, H. A.et al. Concentrations of non esterified fatty acids and glucose in blood of periparturient dairy cows are indicative of pregnancy success at first insemination. Journal of Dairy Science, v. 96, p.181-188, 2013. https://doi.org/10.3168/jds.2012-5619

GUY, M. A.et al. Effects of unilateral prepartum milking on concentrations of immunoglobulin G1 and prolactin in colostrum. Journal of Dairy Science, v. 77, p. 3584-3591, 1994. https://doi.org/10.3168/jds.S0022-0302(94)77302-1 
GUNAY, A.; GUNAY, U.; ORMAN, A. Effects of retained placenta on the fertility in treated dairy cows. Bulgarian Journal of Agricultural Science, v. 17, n.1, p. 126-131, 2011.

GRANT, R. J.; ALBRIGHT, J. L. Effect of Animal Grouping on Feeding Behavior and Intake of Dairy Cattle. Journal of Dairy Science, 84 (E. Suppl.): E156-E163, 2001. https://doi.o https://doi.org/10.3168/jds.S0022-0302(01)70210-X

GOFF, J. P.; HORST, R. L. Effects of the addition of Potassium or Sodium, but not Calcium, to prepartum rations on milk fever in dairy cows. Journal of Dairy Science, v.80, p. 176-186, 1997. https://doi.org/10.3168/jds.S0022-0302(97)75925-3

GOFF, J. P.; RUIZ, R., HORST, L. Relative acidifying activity of anionic salts commonly used to prevent milk fever. Journal of Dairy Science, v. 87, p. 1245-1255, 2004.

https://doi.org/10.3168/jds.S0022-0302(04)73275-0

GOFF, J. P. Pathophysiology of calcium and phosphorus disorders. Veterinary Clinics of North America: Food Animal Practice, v. 16, p. 319-337, 2008.

GRUMMER, R. R. Impact of changes in organic nutrient metabolism on feeding the transition dairy cow. Journal of Animal Science, v.73, p.2820-2833, 1995.

https://doi.org/10.2527/1995.7392820x

GRUMMER, R. R.; MASHEK, D. G.; HAYIRLI, A. Dry matter intake and energy balance in the transition period. Veterinary Clinics of North America: Food Animal Practice, v. 20, n.3, p. 447-470, 2004. https://doi.org/10.1016/j.cvfa.2004.06.013.

HARDARSON, G. H.; INGVARTSEN, K. L. Energy metabolism in the periparturient dairy cow. Fræðaping landbúnaðarins, v. 25, p. 94-102, 2005.

HAMMON, D. S.et al.Neutrophil function and energy status in Holstein cows with uterine health disorders. Veterinary Immunology and Immunopathology, v.113, p.21-29. 2006. https://doi.org/10.1016/j.vetimm.2006.03.022

HARVATINE, K. J.; BOISCLAIR, Y. R.; BAUMAN, D. E. Recent advances in the regulation of milk fat synthesis. Animal, v. 3, p. 40-54, 2009. https://doi.org/10.1017/S1751731108003133

HORST R L, GOFF J P, MCCLUSKEY B. Prevalence of subclinical hypocalcemia in U.S. dairy operations. US Department of Agriculture (USDA) Agricultural Research Service, Washington, DC, 2004

HUTCHINSON, I. A.et al. The effect of strategic supplementation with trans-10, cis-12 conjugated linoleic acid on the milk production, estrous cycle characteristics, and reproductive performance of lactating dairy cattle. Journal of Dairy Science, v. 95, p. 2442-2451, 2012. https://doi.org/10.3168/jds.2011-4632

HUZZEY, J. M.et al. Prepartum behavior and dry matter intake identify dairy cows at risk for metritis. Journal of Dairy Science, v.90, p.3220-3233, 2007. https://doi.org/10.3168/jds.2006$\underline{807}$

KAY, J.K.et al. 2006. Effects of dietary conjugated linoleic acid on production and metabolic parameters in transition dairy cows grazing fresh pasture. J. Dairy Res. 73, 367-377.

https://doi.org/10.1017/S0022029906001944 
KASIMANICKAM, R.et al. Endometrial cytology and ultrasonography for the detection of subclinical endometritis in postpartum dairy cows. The Riogenology, v. 62, n. 1/2, p. 09-23, 2004. https://doi.org/10.1016/j.theriogenology.2003.03.001

KRAUSE, K.M.; OETZEL, G.R. Understanding and preventing subacute ruminal acidosis in dairy herds: A review. Animal Feed Science and Technology, v. 126, n. 3, p. 215-236, 2006. https://doi.org/10.1016/j.anifeedsci.2005.08.004

KEHRLI, M. E. Jr.; NONNECKE, B. J.; ROTH, J.A. Alterations in bovine neutrophil function during the periparturient period. American Journal of Veterinary Research, v. 50, p. 207-214, 1989.

KIM, I. H.; SUH, G. H. Effect of the Amount of Body Condition Loss from the dry to near Calving Period on the Subsequent Body Condition Change, Occurrence of Postpartum Diseases, Metabolic Parameters and Reproductive Performance in Holstein Dairy Cows. Theriogenology, v. 60, p.1445-1456, 2003. https://doi.org/10.1016/S0093-691X(03)00135-3

KRUG, C.et al. Incomplete Milking in Early Lactation Does Not Affect Dairy Cows Resting Behaviors: Results from a Randomized Controlled Trial. Frontiers in Veterinary Science, v. 4, p. 66, 2017. https://doi.org/10.3389/fvets.2017.00066

INGVARTSEN, K. L.; ANDERSEN, J. B. Integration of metabolism and intake regulation: a review focusing on periparturient animals. Journal of Dairy Science, v. 83, n. 7, p. 1573-1597, 2000. https://doi.org/10.3168/jds.S0022-0302(00)75029-6

INGVARTSEN, K. L.; MOYES, K. Nutrition, immune function and health of dairy cattle. Animal, v. 7, n. 1, p. 112-122, 2013. https://doi.org/10.1017/S175173111200170X

IWERSEN, M.et al. Evaluation of an electronic cowside test to detect subclinical ketosis in dairy cows. Journal of Dairy Science, v.92, n.6, p. 2618-2624, 2009. https://doi.org/10.3168/jds.2008$\underline{1795}$

LACASSE, P.et al. Addition of protected and unprotected fish oil to diets for dairy cows. I. Effects on the yield, composition and taste of milk. Journal of Dairy Research, v. 69, p. 511520, 2002.

LACASSE, P.et al. New insights into the importance of prolactin in dairy ruminants. Journal of Dairy Science, v. 99, p. 864-874, 2016. https://doi.org/10.3168/jds.2015-10035

LEBLANC, S. J.; LESLIE K. E.; DUFFIELD T. F. Metabolic predictors of displaced abomasum in dairy cattle. Journal of Dairy Science, v. 88, p. 159-170, 2005.

https://doi.org/10.3168/jds.S0022-0302(05)72674-6

LUCY, M. C.et al. Somatotropic axis components and nutrient partitioning in genetically diverse dairy cows managed under different feed allowances in a pasture system. Journal of Dairy Science, v. 92, p. 526-539, 2009. https://doi.org/10.3168/jds.2008-1421

LIMA, J. A. M. Desempenho produtivo de vacas F1 Holandês/Zebu submetidas ao aumento do número de ordenha no início da lactação e a diferentes manejos de alimentação. 2011. 79f. Dissertação (Mestrado em Zootecnia) - Escola de Veterinária, Universidade Federal de Minas Gerais, Belo Horizonte. 
LITHERLAND, N. B.; DANN, H. M.; HANSEN, A. S.; DRACKLEY, J. K.

Prepartum nutrient intake alters metabolism by liver slices from peripartal dairy cows. Journal of Dairy Science, v. 86, n. 1, p.105-106, 2003. https://doi.org/10.3168/jds.2010-3220

LOISELLE, M. C.et al. Impact of postpartum milking frequency on the immune system and the blood metabolite concentration of dairy cows. Journal of Dairy Science, v. 92, p. 1900-191, 2009. https://doi.org/10.3168/jds.2008-1399

MCNAMARA, S.et al. Effect of milking frequency in early lactation on energy metabolism, milk production and reproductive performance of dairy cows. Livestock Science, v. 117, p.70-78, 2008. https://doi.org/10.1016/j.livsci.2007.11.013

MOYES, K. M.et al. Identification of potential markers in blood for the development of subclinical and clinical mastitis in dairy cattle at parturition and during early lactation. Journal of Dairy Science, v. 92, p. 5419-5428, 2009. https://doi.org/10.3168/jds.2009-2088

MORIN, P.A.et al. A randomized clinical trial to evaluate the effectiveness of incomplete milking in early lactation to reduce ketonemia and hyperketonemia. 29th World Buiatrics Congress, Dublin, Ireland, p. 185. 2016.

NATIONAL RESEARCH COUNCIL. In: 7th Revised Edition of Nutrient Requirements of Dairy Cattle. National Academy Press, Washington, DC, 2001.

NAFIKOV, R. A.et al. Prevention of Fatty Liver in Transition Dairy Cows by Subcutaneous Injections of Glucagon. Journal of Dairy Science, v. 89, n. 5, p. 1533-1545, 2006. https://doi.org/10.3168/jds.S0022-0302(06)72221-4

NONNECKE, B. J.et al. Effects of the mammary gland on functional capacities of blood mononuclear leukocyte populations from periparturient cows. Journal of Dairy Science, v. 86, p. 2359-2368, 2003. https://doi.org/10.3168/jds.S0022-0302(03)73829-6

OLIVEIRA, M. V. M. et al. Influência da monensina no consumo e na fermentação ruminal em bovinos recebendo dietas com teores baixo e alto de proteína. Revista Brasileira de Zootecnia, v. 34, n. 5, p. 1763-1774, 2005.

OETZEL, G. R. Oral Calcium Supplementation in Peripartum Dairy Cows. Veterinary Clinics of North America: Food Animal Practice, v. 29, p. 447-455, 2013.

https://doi.org/10.3168/jds.2017-12917

ODENS, L. J.et al.Effects of varying doses of supplemental conjugated linoleic acid on production and energetic variables during the transition period. Journal of Dairy Science, v. 90, p. 293-305, 2007. https://doi.org/10.3168/jds.S0022-0302(07)72630-9

O'DRISCOLL, K.et al. Reduction in milking frequency and feed allowance improves dairy cow immune status. Journal of Dairy Science, v. 95, p. 1177-1187. 2012.

https://doi.org/10.3168/jds.2011-4408

OLLIER, S.; ZHAO, X.; LACASSE, P. Effects of feed restriction and prolactin-release inhibition at drying off on metabolism and mammary gland involution in cows. Journal of Dairy Science, v. 97, p. 4942-4954, 2014. https://doi.org/10.3168/jds.2014-7914

ORTOLANI, E. L. Enfermidades do Período de Transição. In: VIII Congresso Brasileiro de Buiatria. Anais do VIII Congresso Brasileiro de Buiatria, 2009. Disponível em: http://www.revistas.ufg.br/index.php/vet/article/view/7660/5433. Acesso em: 4 maio 2019. 
OSPINA, P. A.et al. Evaluation of nonesterified fatty acids and $\beta$-hydroxybutyrate in transition dairy cattle in the northeastern United States: Critical thresholds for prediction of clinical diseases. Journal of Dairy Science, v. 93, p. 546-554, 2010. https://doi.org/10.3168/jds.2009$\underline{2277}$

OVERTON, T.R.; WALDRON, M.R. Nutritional Management of Transition Dairy Cows: Strategies to Optimize Metabolic Health. Journal of Dairy Science, v.87, E. Suppl, p. E104-119, 2004. https://doi.org/10.3168/jds.S0022-0302(04)70066-1

PLAZIER, J. C.; MARTIN, A.; DUFFIELD, T. Effect of a prepartum administration of monensin in a controlled capsule on apparent digestibilities and nitrogen utilization in transition dairy cows. Journal of Dairy Science, v. 83, p. 2906-2918, 2000. https://doi.org/10.3168/jds.S0022$\underline{0302(00) 75192-7}$

PETZOLD, M.et al. Impacts of CLA and dietary concentrate proportion on blood metabolite concentration and proliferation of peripheral blood mononuclear cells of periparturient dairy cows. Animal, v. 9, p. 481-489, 2015. https://doi.org/10.1017/S175173111400264X

PHYN, C.V.C.et al.Temporary alterations to postpartum milking frequency affect wholelactation milk production and the energy status of pasture-grazed dairy cows. Journal of Dairy Science, v. 97, p. 6850-6868, 2014. https://doi.org/10.3168/jds.2013-7836

RABELO, E.; CAMPOS, B. Fisiologia do Período de Transição. Ciência Animal Brasileira, v. 1, 21 out. 2009.

RAIZMAN, E.A.; SANTOS, J.E.P. The Effect of Left Displacement of Abomasum Corrected by Toggle-Pin Suture on Lactation, Reproduction, and Health of Holstein Dairy Cows. Journal of Dairy Science, v. 85, p.1157-1164, 2002. https://doi.org/10.3168/jds.S0022-0302(02)74178-7

RADOSTITS, O. M. et al. Veterinary Medicine. A textbook of the diseases of cattle, sheep, pigs, goats and horses. 9.ed. London: W.B. Saunders, 2000. p.867-891

RASTANI, R. R.et al. Effects of increasing milking frequency during the last 28 days of gestation on milk production, dry matter intake, and energy balance in dairy cows. Journal of Dairy Science, v. 90, p. 729-1739, 2007. https://doi.org/10.3168/jds.2006-475

REINHARDT, T. A.et al. Prevalence of subclinical hypocalcemia in dairy herds. Veterinary Journal, v. 188, p.122-124, 2011. https://doi.org/10.3168/jds.2018-14587

REYNOLDS, C. K.et al.Splanchnic metabolism of dairy cows during the transition from late gestation through early lactation. Journal of Dairy Science, v. 86, p.1201-1217, 2003. https://doi.org/10.3168/jds.S0022-0302(03)73704-7

ROCHE, J.F. The effect of nutritional management of the dairy cow on reproductive efficiency. Animal Reproduction Science, v. 96, p.282-296, 2006.

https://doi.org/10.1016/j.anireprosci.2006.08.007

ROCHE J. R.; FRIGGENS, N. C.; KAY, J. K. Berry Invited review: Body condition score and its association with dairy cow productivity, health, and welfare. Journal of Dairy Science, v. 92, p. 5769-5801, 2009. https://doi.org/10.3168/jds.2009-2431

SANTOS, J. E. P.et al. Effect of prepartum milking of primigravid cows on mammary gland health and lactation performance. Livestock Production Science, v. 86, p.105-116, 2004. https://doi.org/10.1016/S0301-6226(03)00149-0 
SCHÄFERS, S.et al. Influence of conjugated linoleic acid and vitamin E on performance, energy metabolism, and change of fat depot mass in transitional dairy cows. Journal of Dairy Science, v. 100, p. 3193-3208, 2017. https://doi.org/10.3168/jds.2017-13071

SCHLAMBERGER, G.et al. 2010. Effects of continuous milking during the dry period or once daily milking in the first 4 weeks of lactation on metabolism and productivity of dairy cows. Journal of Dairy Science, v. 93, 2471-2485. https://doi.org/10.3168/jds.2009-2823

SHELDON, I. M. The postpartum uterus. Veterinary Clinics of North America: Food Animal Practice, v. 20, p. 569-591, 2004.https://doi.org/10.1016/j.cvfa.2004.06.008

SHELDON, I. M.et al.O. Defining postpartum uterine disease in cattle. Theriogenology, v. 65, p. 1516-1530, 2006. https://doi.org/10.1016/j.theriogenology.2005.08.021

SHELDON, I. M.et al. Defining postpartum uterine disease and the mechanisms of infection and immunity in the female reproductive tract in cattle. Biology of Reproduction, v. 81, v.6, p.10251032, 2009.

SCHIRMANN, K.et al. Short communication: Rumination and feeding behaviors differ between healthy and sick dairy cows during the transition period. Journal of Dairy Science, v. 99, v. 12, p.9917-9924. 2016.DOI: https://doi.org/10.3168/jds.2015-10548

SCHWARTZKOPF-GESWEIN, K.S. et al.Effect of bunk management of feed behavior, ruminal acidosis and performance of feedlot cattle: a review. Journal Animal Science, Suppl. 2. v. 81, p. E149-E158, 2003. https://doi.org/10.2527/2004.82113357x

SCHÜTZ, L. F. Doenças Metabólicas como Causa de Transtornos Reprodutivos no Gado Leiteiro. 2007. 31f. Monografia- Universidade Federal do Rio Grande do Sul (UFRGS)Faculdade de Veterinária. Porto Alegre.

SNIFFEN. C. J. Grouping management and physical facilities. In The Veterinary Clinics of North America - Food Animal Practice. Vol. 7(2):465. 1991.

SELBERG, K.T.et al. Production and metabolic responses of periparturient Holstein cows to dietary conjugated linoleic acid and trans-octadecenoic acids. Journal of Dairy Science, v. 87, 158-168, 2004. https://doi.org/10.3168/jds.S0022-0302(04)73153-7

SEPULVEDA-VARAS, P. D. M.et al. Transition diseases in grazing dairy cows are related to serum cholesterol and other analytes. PLoS One, v. 10, n.3, p. e0122317, 2015. https://doi.org/10.1371/journal.pone.0122317

SORDILLO, L. M.; RAPHAEL, W. Significance of Metabolic Stress, Lipid Mobilization, and Inflammation on Transition Cow Disorders. Veterinary Clinics: Food Animal, v. 29, p. 267 278, 2013. https://doi.org/10.1016/j.cvfa.2013.03.002

SIGL, T.et al. Rumen-protected conjugated linoleic acid supplementation to dairy cows in late pregnancy and early lactation: Effects on milk composition, milk yield, blood metabolites and gene expression in liver. Acta Veterinaria Scandinavica, v. 52, p.16-25, 2010. https://doi.org/10.1186/1751-0147-52-16

STER, C.; LOISELLE, M. C.; LACASSE, P. Effect of postcalving serum nonesterified fatty acids concentration on the functionality of bovine immune cells. Journal of Dairy Science, v. 95, p. 708-717, 2012. https://doi.org/10.3168/jds.2011-4695 
VAN WINDEN, S. C. L.et al. Feed Intake, Milk Yield, and Metabolic Parameters Prior to Left displaced Abomasum in Dairy Cows. Journal of Dairy Science, v. 86, p. 1465-1471, 2003. https://doi.org/10.3168/jds.S0022-0302(03)73730-8

WALSH, R. B.et al. The Effect of Subclinical Ketosis in Early Lactation on Reproductive Performance of Postpartum Dairy Cows. Journal of Dairy Science, v. 90, n. 6, p. 2788-2796, 2007. https://doi.org/10.3168/jds.2006-560

WEICH, W.; BLOCK, E.; LITHERLAND, N. B. Extended negative dietary cation-anion diferrence feeding does not negatively affect postpartum performance of multiparous dairy cows. Journal of Dairy Cows, v. 96, p. 5780-5792, 2013. https://doi.org/10.3168/jds.2012-6479

WITTIWER, F. Diagnóstico dos desequilíbrios metabólicos de energia em rebanhos bovinos. In: GONZÁLEZ, F. H. D.et al. (Eds). Perfil metabólico em ruminantes: seu uso em nutrição e doenças nutricionais. Porto Alegre, Brasil. Editora UFRGS, 108p. 2000. 